\title{
Chiroptical properties of 1,3-diphenylallene-anchored tetrathiafulvalene and its polymer synthesis
}

\author{
Masashi Hasegawa ${ }^{* 1}$, Junta Endo ${ }^{1}$, Seiya Iwata ${ }^{1}$, Toshiaki Shimasaki ${ }^{2}$ \\ and Yasuhiro Mazaki ${ }^{* 1}$
}

\section{Full Research Paper}

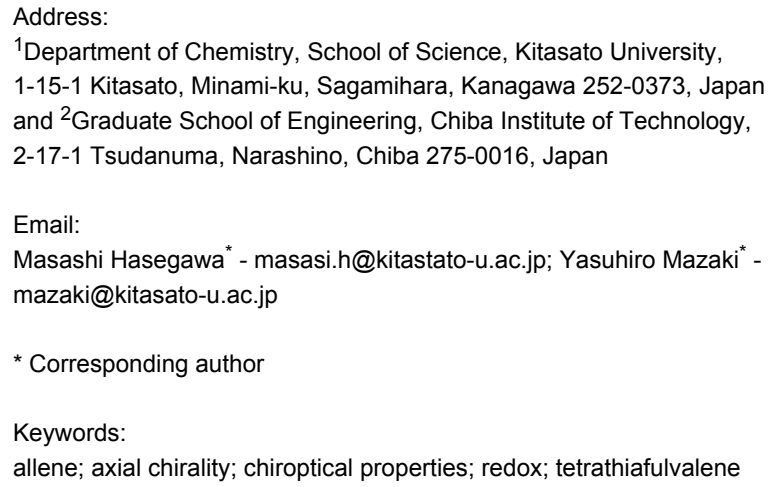

${ }^{1}$ Department of Chemistry, School of Science, Kitasato University, 1-15-1 Kitasato, Minami-ku, Sagamihara, Kanagawa 252-0373, Japan and ${ }^{2}$ Graduate School of Engineering, Chiba Institute of Technology, 2-17-1 Tsudanuma, Narashino, Chiba 275-0016, Japan

Email:

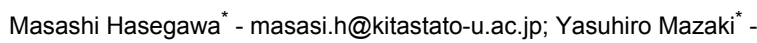
mazaki@kitasato-u.ac.jp

* Corresponding author

Keywords:

allene; axial chirality; chiroptical properties; redox; tetrathiafulvalene

\author{
Beilstein J. Org. Chem. 2015, 11, 972-979. \\ doi:10.3762/bjoc.11.109
}

Received: 23 February 2015

Accepted: 13 May 2015

Published: 08 June 2015

This article is part of the Thematic Series "Tetrathiafulvalene chemistry".

Guest Editor: P. J. Skabara

(C) 2015 Hasegawa et al; licensee Beilstein-Institut. License and terms: see end of document.

\begin{abstract}
A novel tetrathiafulvalene dimer, bridged by a chiral 1,3-diphenylallene framework, has been prepared as an optically active compound having strong chiroptical properties. Although a chiral allene bearing strong electron-donating group(s) often undergoes slow photoracemization even in daylight, the present allene is totally configurationally stable under ordinary conditions. Each isomer possesses pronounced chiroptical properties in its ECD spectra reflecting the chiral allene framework. Moreover, the elongation of the chiral main chain was also carried out by direct $\mathrm{C}-\mathrm{H}$ activation of the TTF unit, and the chiroptical properties of the resulting polymer were also investigated.
\end{abstract}

\section{Introduction}

Recently, there has been a growing interest in chiral $\pi$-conjugated systems having strong chiroptical properties because they have great potential for use in optical devices involving polarized light [1-3]. Chiral response, in electronic circular dichroism (ECD) based on an exciton coupling between two adequate $\pi$-chromophores, can express a pronounced chiroptical effect over various optical energy regions. Therefore, embedding the chromophores into a chiral rigid framework can be a practical molecular design for ascertaining chiroptical materials [4-7].
A symmetric allene framework is one of the most reliable chiral resources that can preserve a consistent orientation of the chromophores [8,9]. We recently introduced 1,3-bis(tetrathiafulvalenyl)allene derivatives $\mathbf{1}$, as a new class of chiral electrochromic (EC) materials consisting of redox-active chromophores and a non-centrochiral framework (Figure 1) [10]. The intensive Cotton effect on the ECD spectra is switchable by tuning the electronic structure of the tetrathiafulvalene (TTF) moieties. However, compound $\mathbf{1}$ exhibited slow racemization in 

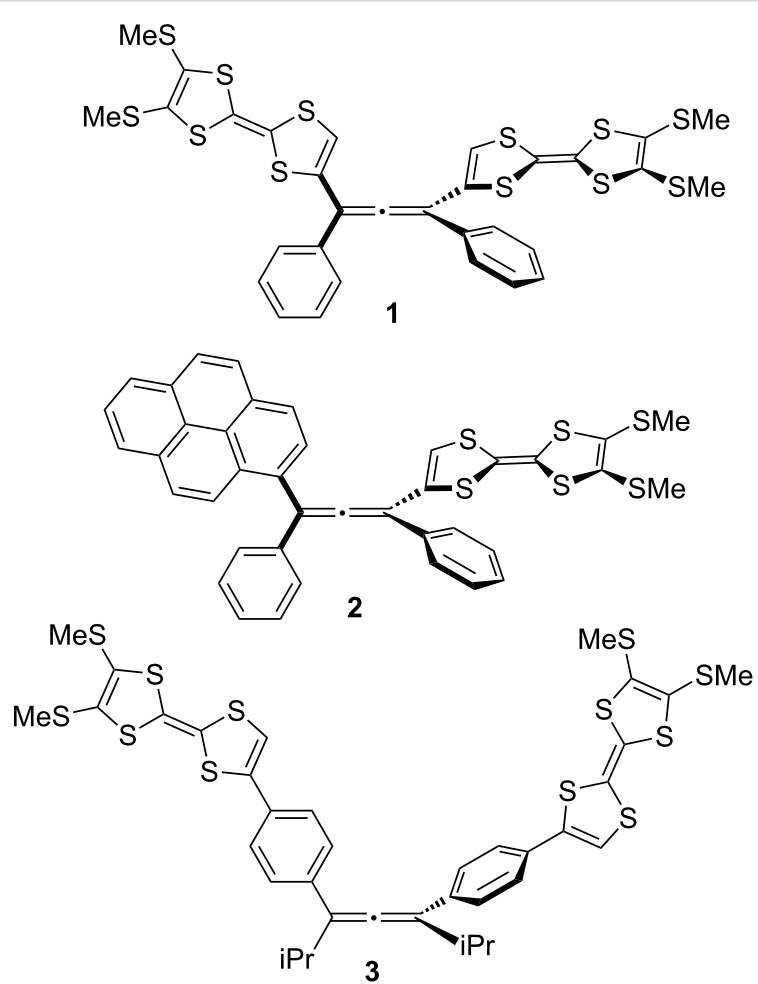

Figure 1: TTF-substituted allenes 1-3.

solution under daylight. The chirality of an allene is configurationally firm in general, because the barrier of the rotation of the allenic double bonds is quite high $\left(\Delta G^{\ddagger}=180 \mathrm{~kJ} \mathrm{~mol}^{-1}\right.$ for $\mathrm{CH}_{3} \mathrm{CH}=\mathrm{C}=\mathrm{CHCH}_{3}$ ) [11]. In contrast, several allenes directly connected with electron-donating groups occasionally underwent photoracemization $[12,13]$. Although the mechanism of the photoracemization is not clear, a comparative examination of the racemization rate in $\mathbf{1}$ and $\mathbf{2}$, the latter of which is a dissymmetric allene having a TTF and a pyrenyl group at 1,3position, suggests that the direct connection of the TTF units may strongly affect the fast racemization [14]. From this point of view, we decided to employ a 1,3-diphenylallene derivative (3) as a stable chiral framework. We conceive that the insertion of the phenylene units between the central chiral allene and TTFs would overcome the vulnerability toward the photoracemization under ambient conditions. Previsously, Krause and co-workers reported the first synthesis of a cyclic allenophane involving a racemic 1,3-diphenyl allene unit [15]. In addition, Fallis and co-workers synthesized a cyclic oligoallene based on a chiral 1,3-diphenylallene [16]. More recently, Kijima and co-workers reported the use of a racemic 1,3-diphenylallene framework as a new building block for a $\pi$-conjugated polymer [17]. However, there have been few investigations regarding the use of 1,3-diphenylallene as a chiral source and involving the detailed investigations of the chiroptical property. In this paper, we report the synthesis of chiral 1,3-bis(4-(tetrathiafulvalenenyl)phenyl)allene derivative $\mathbf{3}$ and its chiroptical properties. Furthermore, the first synthesis of a chiral copolymer containing TTFs based on a chiral allenic framework (poly-3: PTDPA is also demonstrated.

\section{Results and Discussion}

To anchor the TTF groups into the allene framework, we chose a cross-coupling reaction of unknown 1,3-bis(4-iodophenyl)1,3-diisopropylallene (9) with a TTF-zinc intermediate (Scheme 1). Previously, 1,3-bis(2-bromophenyl)allene derivatives were reported by Ready et al. as a precursor of an asymmetric catalyst [18]. To obtain the chiral 1,3-bis(4-bromophenyl)allene (8) in a larger scale, we modified the synthesis and the chiral separation process as shown in Scheme 1. Thus, starting with 1-(4-bromophenyl)-2-methylpropanone (4), which<smiles>C#CC(O)(c1ccc(Br)cc1)c1ccc(C(C)(F)F)cc1</smiles>

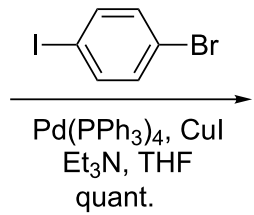<smiles>CC(C)(C#Cc1ccc(Br)cc1)C(O)(C#Cc1ccc(Br)cc1)c1ccc(Br)cc1</smiles>

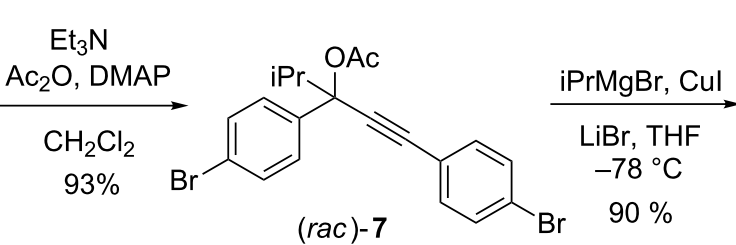

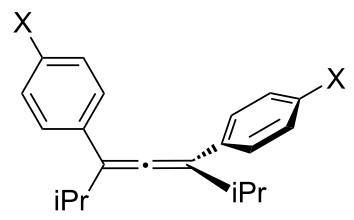

$\begin{array}{cl}(r a c)-8(X=B r) \square & \text { 1) } t \text {-BuLi, ether } \\ -78{ }^{\circ} \mathrm{C} \\ \text { (rac )-9 }(X=1) \longleftarrow & \text { 2) } \mathrm{C}_{6} \mathrm{~F}_{13} \mathrm{l} \\ 92 \%\end{array}$<smiles></smiles>

$89 \%$ 
was prepared from bromobenzaldehyde (see Supporting Information File 1), which upon treatment with lithium acetylide at low temperature gave racemic propargyl alcohol 5 in 94\% yield. Sonogashira coupling reaction of $\mathbf{5}$ with 4-bromoiodobenzene gave compound $\mathbf{6}$ quantitatively. The treatment of $\mathbf{6}$ with $\mathrm{Ac}_{2} \mathrm{O}$ and a catalytic amount of $N, N$-dimethyl-4-aminopyridine (DMAP) gave the acetyl ester 7 in $93 \%$ yield. The formation of 1,3-bis(4-bromophenyl)-1,3-diisopropylallene (8) was achieved by an $\mathrm{S}_{\mathrm{N}} 2$ '-type reaction of 7 with iPrMgCl-CuI- $\mathrm{LiBr}$ at low temperature in $90 \%$ yield. This allene was easily transformed into the precursor 9 by halogen exchange with $t$-BuLi followed by the addition of $\mathrm{C}_{6} \mathrm{~F}_{13} \mathrm{I}$ in $92 \%$ yield. Subsequently, the reaction of the diiodo precursor 9 with 2 equiv of an organozinc species derived from 4,5-bis(methylthio)TTF [19] in the presence of $\mathrm{Pd}\left(\mathrm{PPh}_{3}\right)_{4}$ gave racemic compound 3 in good yield $(89 \%)$. In the ${ }^{13} \mathrm{C}$ NMR spectrum, the allenic $=\mathrm{C}=$ carbon was found to be at $204 \mathrm{ppm}$, which is a typical value of the linear allene framework. In addition, the FTIR spectrum also exhibited a reasonable vibrational stretching of the $\mathrm{C}=\mathrm{C}=\mathrm{C}$ unit at $1914 \mathrm{~cm}^{-1}$.

Because new symmetrical allenes were subject to optical resolution, the separation of ( $\mathrm{rac}$ )-3 was carried out by using a recycling HPLC method on a chiral stationary phase (DAICEL Chiralpak IA-3) with hexane/ $\mathrm{CHCl}_{3} / \mathrm{EtOH}(\mathrm{v} / \mathrm{v}=20: 10: 0.2)$ elution. Thus, equimolecular amounts of the optically pure allenes $(+)-\mathbf{3}$ and $(-)-3$, whose optical rotations $\left([\alpha]_{\mathrm{D}}{ }^{25}\right)$ are +726 (c 0.853 in $\mathrm{CH}_{2} \mathrm{Cl}_{2}$ ) and $-721\left(c 0.853\right.$ in $\mathrm{CH}_{2} \mathrm{Cl}_{2}$ ), respectively, were collected. Similarly, optical resolution of $(\mathrm{rac})-$ 9 also provided $(+) /(-)-9$ with optical rotations $\left([\alpha]_{\mathrm{D}}{ }^{25}\right)$ of +338 (c 0.83 in $\mathrm{CH}_{2} \mathrm{Cl}_{2}$ ) and -341 (c 0.83 in $\mathrm{CH}_{2} \mathrm{Cl}_{2}$ ), respectively.

Figure 2 depicted the electronic circular dichroism (ECD) spectra of the enantiomers of $(+) /(-)-3$ and $(+) /(-)-9$, and their UV-vis absorption spectra. The ECD spectrum of the (-)-9 enantiomer exhibited a clear bisignate CD curve with a negative peak at $274 \mathrm{~nm}$ and a positive peak at $248 \mathrm{~nm}$. According to the chiral exciton coupling method [20], the spectrum trend of (-)-9 suggests that the isomer should have the $(R)$-configuration. This assignment was also validated by spectral simulation, obtained from the electronic transition energies and the rotational strengths using TD-DFT calculations [21]. Thus, the intensive Cotton effect is associated with the exciton coupling of the two chromophores of the iodobenzene units. In the ECD spectrum of (+)-9, the mirror image of the trend lines of $(-)-9$ was found.

The UV-vis absorption spectrum of $\mathbf{3}$ exhibits absorption maxima at 314 and $405 \mathrm{~nm}$. In the ECD spectra of $(+) /(-)-3$, the Cotton effect was observed over the entire absorption range. A simulated spectrum of $\mathbf{3}$ with the $(R)$-configuration, calculated

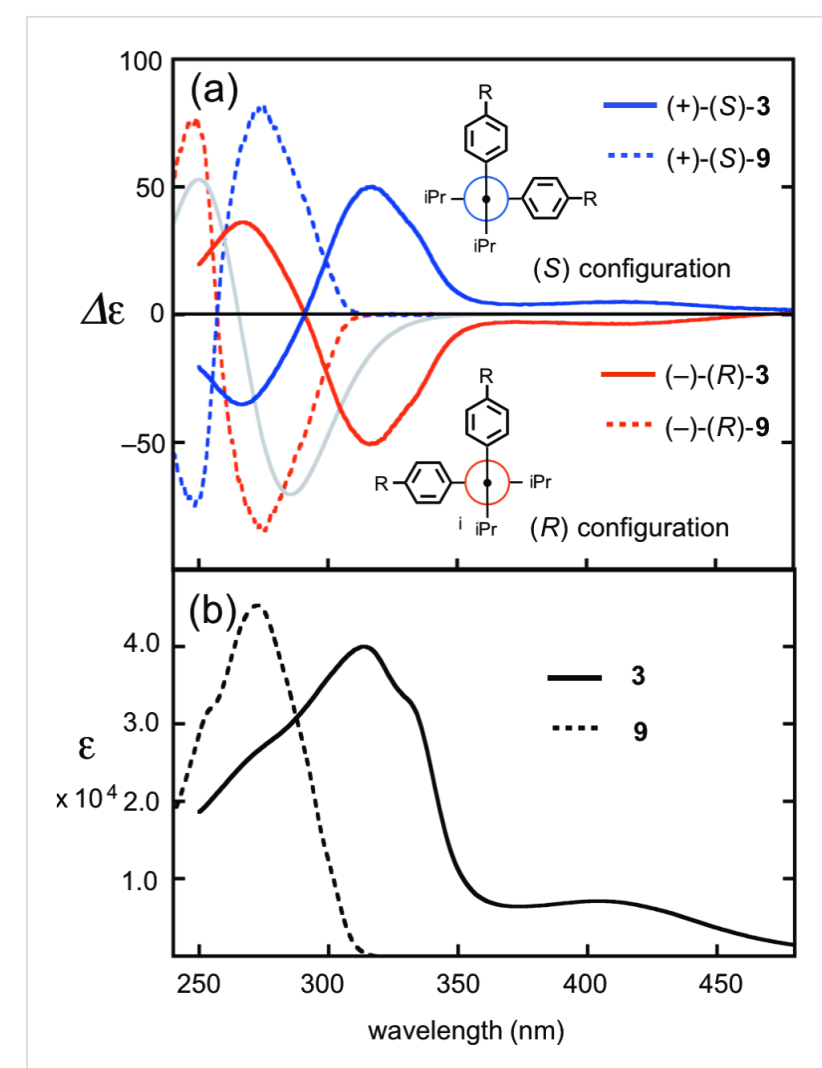

Figure 2: (a) ECD spectra of $(R)-(-)-3\left(3.5 \times 10^{-5} \mathrm{M}\right),(S)-(+)-3$ $\left(3.8 \times 10^{-5} \mathrm{M}\right),(R)-(-)-9\left(3.0 \times 10^{-5} \mathrm{M}\right)$, and $(S)-(+)-9\left(2.9 \times 10^{-5} \mathrm{M}\right)$ in $\mathrm{CH}_{2} \mathrm{Cl}_{2}$ together with the simulated ECD spectra of 3 and 9 in $(R)$-configuration. (b) UV spectra of $\mathbf{3}\left(3.5 \times 10^{-5} \mathrm{M}\right)$ and $\mathbf{9}\left(3.8 \times 10^{-5} \mathrm{M}\right)$ in $\mathrm{CH}_{2} \mathrm{Cl}_{2}$.

by TD-DFT (B3LYP/6-31G(d,p)), has moderate resemblance to the spectrum obtained from (-)-3. This result is also consistent with the hypothesis from the chiral exciton coupling method. To solidify the absolute configuration, the synthesis of $(R)-3$ from (R)-9 was carried out separately, and the ECD spectrum of the product from $(R)-\mathbf{3}$ was in complete accord with that of (-)-9. Therefore, the absolute configuration of $(+)-\mathbf{3}$ and (-)-3 should be $(+)-(S)-3$ and $(-)-(R)-3$, respectively. In the spectra, the intensive Cotton effect was observed at 270 and $316 \mathrm{~nm}$ as a bisignate couple, together with broad shoulder tails to ca. $500 \mathrm{~nm}$. The Cotton effect associated with the HOMO-LUMO transition was relatively weak, presumably due to the longrange coupling between two TTF units in the chiral situation. Although allenes $\mathbf{1}$ and $\mathbf{2}$, reported previously, underwent quick photoracemization, the present allenes, $\mathbf{3}$ and $\mathbf{9}$, exhibit photochemical stability without racemization in common organic solvents. It clearly suggests that the insertion of the phenylene units effectively prevents racemization.

To examine the potential of the 1,3-diphenylallene frameworks as a stable chiral resource, a chiral alternate copolymer consisting of TTF and chiral diphenylallene (PTDPA) was 
prepared, and its chiroptical properties were investigated. Previously, a racemic conjugated polymer in the literature was prepared by a Suzuki-Miyaura or Yamamoto coupling reaction from ( $\mathrm{rac}$ )-8 [17]. In contrast, to the best of our knowledge, there is no example of a chiral polymer based on the 1,3-diphenylallene frameworks that can be a unit of copolymer with various types of aryl groups. At this point, we have chosen the direct arylation of TTF in the presence of a palladium catalyst as a key reaction for the chiral polymer synthesis (Scheme 2) [22]. Thus, the chiral allenes, $(R)-\mathbf{9}$ or $(S)-\mathbf{9}$, react with an active palladium species, prepared in situ from $\mathrm{Pd}(\mathrm{OAc})_{2}$ and $\mathrm{P}(t-\mathrm{Bu})_{3} \cdot \mathrm{HBF}_{4}$ salt in the presence of $\mathrm{CsCO}_{3}$, to give the chiral copolymer of $(R)$-PTDPA and ( $S$ )-PTDPA, respectively, after purification by column chromatography on polystyrene Biobeads. By using gel permeation chromatography (GPC), the number-average molecular weights $\left(M_{\mathrm{n}}\right)$ of the collected PTDPA were in the range of $2800-5600 \mathrm{~g} \mathrm{~mol}^{-1}$ with polydispersity index (PDI) values between 1.01-1.54. These polymers solubilized well in common organic solvents, and they were characterized by their NMR spectra.

Figure 3 depicts normalized UV-vis absorption and ECD spectra of ( $R$ )-PTDPA and (S)-PTDPA, together with $(R)$-3 and $(S)$-3. The polymer exhibited absorption maxima at $310 \mathrm{~nm}$ and shoulder absorption at ca. $415 \mathrm{~nm}$, extending up to $600 \mathrm{~nm}$. The shape of the spectrum is quite similar to that of the monomer 3 . The ECD spectra of both enantiomeric polymers exhibited the mirror image. There are two intensive Cotton effects at $318 \mathrm{~nm}$ $\left(\lambda_{\text {first }}\right)$ and $254 \mathrm{~nm}\left(\lambda_{\text {second }}\right)$, together with a weak ellipticity in the range of ca. $360-450 \mathrm{~nm}$. The shape of the trend line of PTDPA is similar to that of $\mathbf{3}$ with the same absolute configuration at the allenic moiety except for the small blue shift of the $\lambda_{\text {second }}$ value of PTDPA $(254 \mathrm{~nm})$. Consequently, the chiral situation of the chromophores is preserved in the polymeric structure. However, the Cotton effect associated with the TTF moieties was observed as a relatively weak band, and hence there is not any amplification owing to a higher order structure in the polymer. Moreover, the ECD intensities of both enantiomers did not change under ambient light, at least over several days. Therefore, 1,3-diphenylallene is a reliable chiral source for a chiral polymer having electron-donating units.

(a)

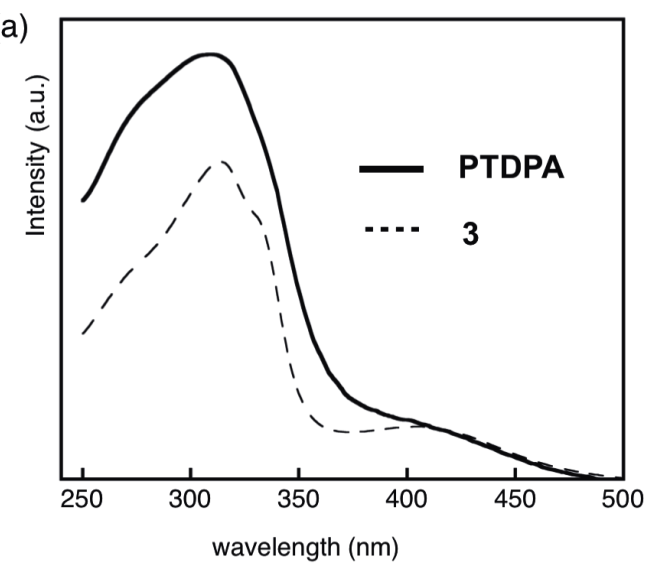

(b)

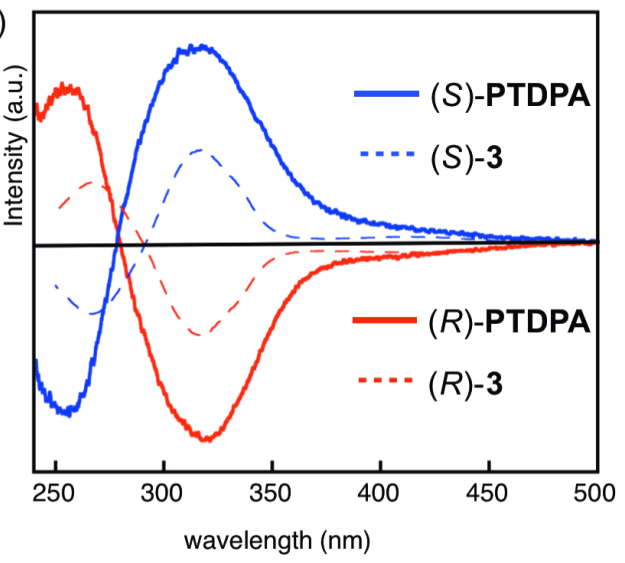

Figure 3: (a) UV-vis absorption spectra of 3 and PTDTA in $\mathrm{CH}_{2} \mathrm{Cl}_{2}$. (b) Normalized ECD spectra of (R)-PTDPA, (S)-PTDPA, $(R)-3$, and (S)-3 in $\mathrm{CH}_{2} \mathrm{Cl}_{2}$.

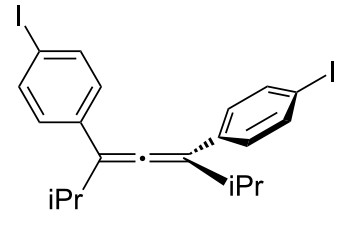

$(R)-9$ or $(S)-9$

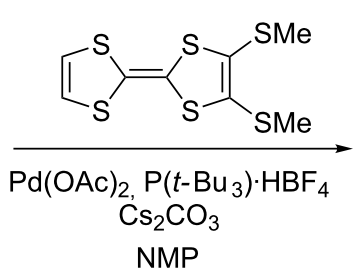

NMP

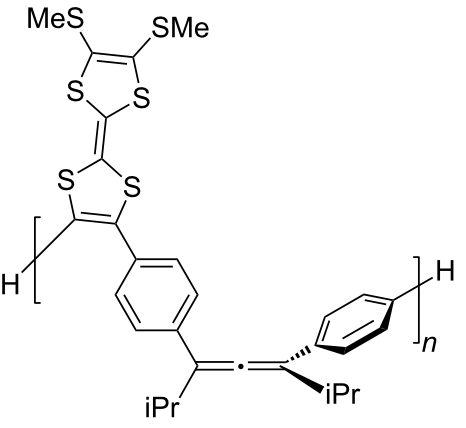

(R)-PTDPA or (S)-PTDPA 
The electrochemical properties of $\mathbf{3}$ and PTDPA were investigated by cyclic voltammetry (CV) analyses (Figure 4 and Table 1). In CVs, there are two sets of reversible redox waves in the conventional potential range. Compound $\mathbf{3}$ exhibits two two-electron transfer waves at $E_{1 / 2}^{1}=-0.01 \mathrm{~V}$ and $E^{2}{ }_{1 / 2}=0.31 \mathrm{~V}$, whereas PTDPA exhibits in a similar manner at $E_{1 / 2}^{1}=0.03 \mathrm{~V}$ and $E_{1 / 2}^{2}=0.30 \mathrm{~V}$. These results suggest that the TTF units in both compounds are oxidized independently to form TTF/TTF ${ }^{\bullet+}$ and, subsequently, $\mathrm{TTF}^{\bullet+} / \mathrm{TTF}^{2+}$. A small positive shift of $E_{1 / 2}^{1}$ in PTDPA is presumably due to the substituent effects of the two phenylene groups in the TTF unit.

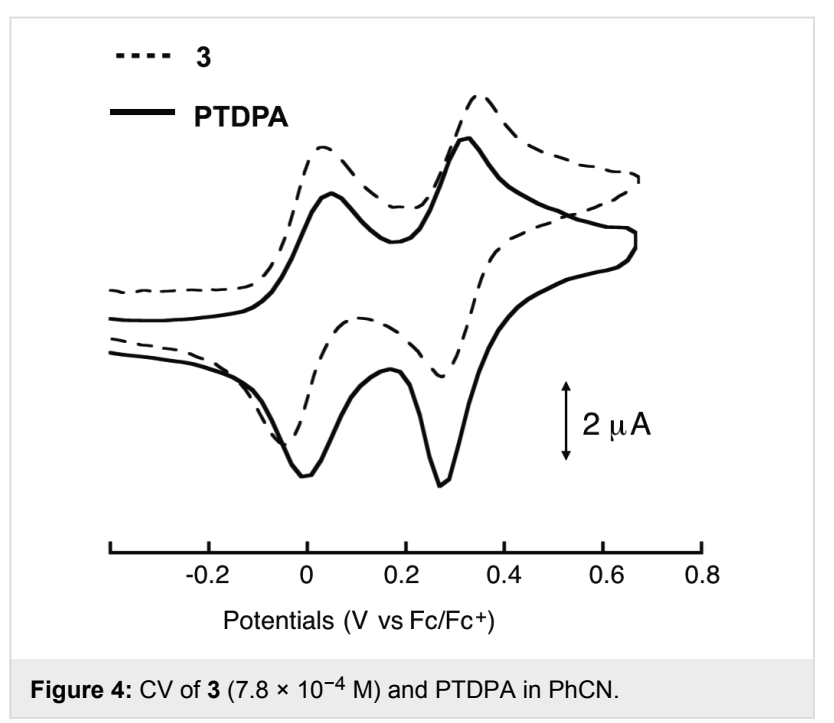

\begin{tabular}{|ccc}
\hline $\begin{array}{c}\text { Table 1: Redox potentials of } \mathbf{3} \text { and PTDPA. } \\
\text { Compound }\end{array}$ & $E^{1} 1 / 2$ & $E^{2} 1 / 2$ \\
\hline 3 & -0.01 & 0.31 \\
PTDPA & 0.03 & 0.30 \\
\hline
\end{tabular}

aln $\mathrm{PhCN}$ containing $0.1 \mathrm{M} \mathrm{n}-\mathrm{Bu}_{4} \mathrm{ClO}_{4}$ at $25^{\circ} \mathrm{C}$. Potentials were measured against an $\mathrm{Ag} / \mathrm{Ag}^{+}$electrode and adjusted to the $\mathrm{Fc} / \mathrm{Fc}^{+}$ potential under identical conditions.

To investigate the electronic structures of $\mathbf{3}$ in various redox states, cationic species of $\mathbf{3}^{2+}$ and $\mathbf{3}^{4+}$ were prepared by their reaction with an adequate amount of $\mathrm{Fe}\left(\mathrm{ClO}_{4}\right)_{3}$, as the oxidant, in a $\mathrm{MeCN} / \mathrm{CH}_{2} \mathrm{Cl}_{2}(\mathrm{v} / \mathrm{v}=1: 4)$ solution (Figure 5a). During the sequential addition of between 0 to 2 equivalents of the oxidant, no isosbestic point was seen other than that of $\mathbf{3} / \mathbf{3}^{2+}$. Therefore, $\mathbf{3}^{2+}$ was formed first other than $\mathbf{3}^{\mathbf{}}$, suggesting that there is few intramolecular interactions between two TTF units through the central 1,3-diphenylallene moiety. The obtained spectrum of $3^{2+}$ is quite similar to those of 4,5-bis(methylthio)tetrathiafulvalenylbenzene radical cation $\mathbf{1 0}^{\mathbf{}}$, which was reported previously [7] (Table 2). In the spectrum of $\mathbf{3}^{2+}$, the absorption maximum at $810 \mathrm{~nm}$ is assigned to an electronic transition to
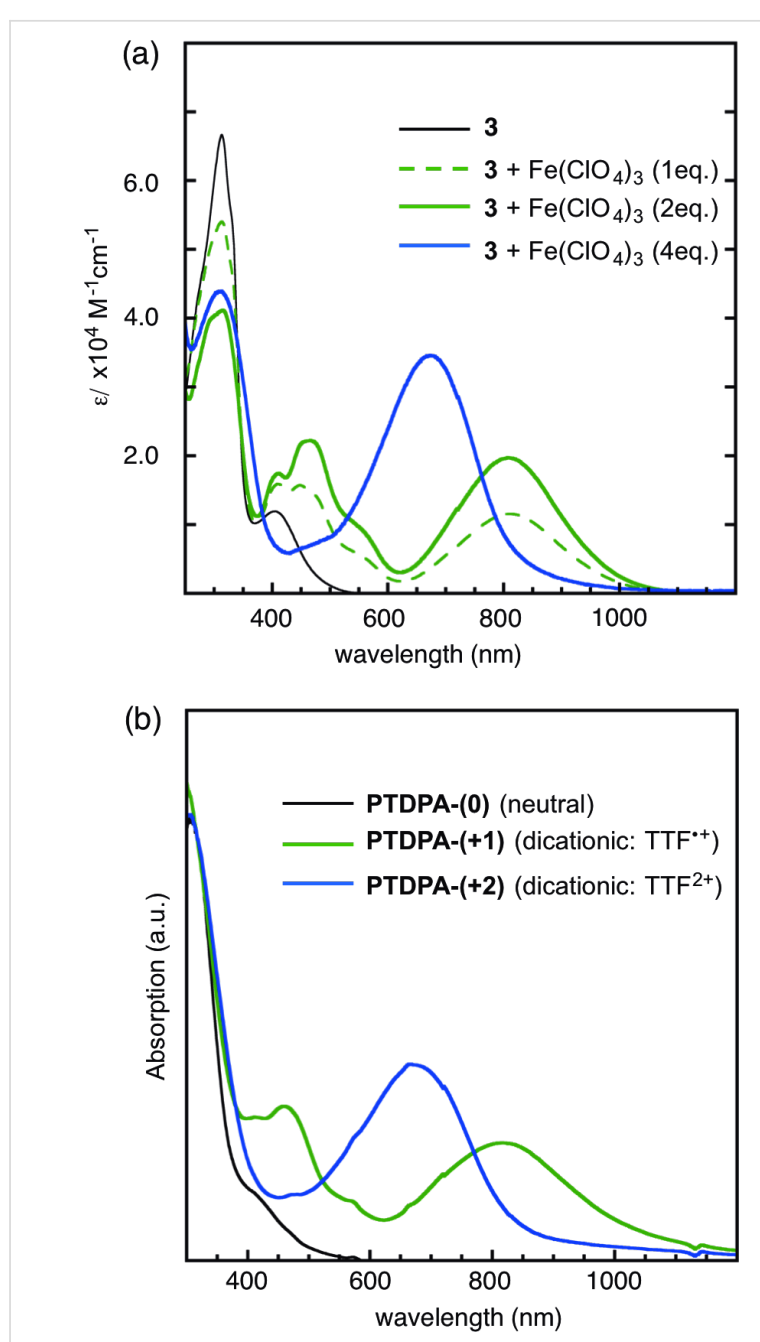

Figure 5: Electronic spectra of (a) 3 and its cationic species, and (b) PTDPA and its cationic states of PTDPA-(+1) and PTDPA-(+2).

the SOMO in the $\mathrm{TTF}^{\cdot+}$ moieties. The value was slightly redshifted compared with that of $\mathbf{1 0}^{\mathbf{*}}(775 \mathrm{~nm})$. This small bathochromic shift can be ascribed to the conjugation to the central allene moiety. As for the spectrum of $\mathbf{3}^{4+}$, the absorption maximum at $667 \mathrm{~nm}$, assigned to the HOMO-LUMO transition in the $\mathrm{TTF}^{2+}$ moieties, was also red-shifted compared with the corresponding absorption maximum $(637 \mathrm{~nm})$ of $\mathbf{1 0}^{2+}$.

Similarly, cationic species of PTDPA were also produced by the sequential addition of $\mathrm{Fe}\left(\mathrm{ClO}_{4}\right)_{3}$ (Figure 5b). During the oxidation, three phases of PTDPA-(0), PTDPA- $(+1)$, and PTDPA$(+2)$, corresponding to the oxidation stages involving TTF, $\mathrm{TTF}^{\bullet+}$, and $\mathrm{TTF}^{2+}$, respectively, were observed during the oxidation. The spectrum of the intermediate phase of PTDPA- $(+1)$ having absorption maxima at 459 and $816 \mathrm{~nm}$ are almost coincident with that of $\mathbf{3}^{2+}$ (Table 2). With excess addition of the oxidant, the third phase of PTDPA- $(+2)$ appeared, and the spectrum was almost identical to $3^{4+}$. The spectral resemblance 


\begin{tabular}{|l|l}
\hline $\begin{array}{l}\text { Table 2: Absorption maxima of } 3,10 \text { and PTDPA. }^{a} \\
\text { Compound }\end{array}$ & $\lambda_{\max }$ \\
\hline $\mathbf{3}$ & $313(66600), 405(11900)$ \\
$\mathbf{3}^{2+}$ & $313(41100), 412(17500), 466$ \\
$\mathbf{3}^{4+}$ & $(22300), 810(19700)$ \\
$10^{\mathrm{b}}$ & $313(43900), 667(34600)$ \\
$\mathbf{1 0}^{\circ+\mathrm{b}}$ & $332(14800), 393(3900)$ \\
$\mathbf{1 0}^{2+\mathrm{b}}$ & $256(18300), 449(11200), 775(8100)$ \\
PTDPA-(0) & $259(21500), 646(17900)$ \\
PTDPA-(+1) & 309,410 \\
PTDPA-(+2) & 459,816 \\
\hline
\end{tabular}

aConditions: in $\mathrm{CH}_{2} \mathrm{Cl}_{2}-\mathrm{MeCN}(\mathrm{v} / \mathrm{v}=4: 1)$ solution at $25^{\circ} \mathrm{C}$. The molecular structure of $\mathbf{1 0}$ is depicted as follow:

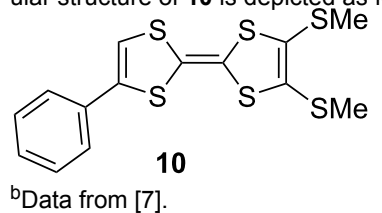

implies that the influence of the central 1,3-diphenylallene on the electronic structure of the TTF units in PTDPA is quite small.

Finally, the ECD spectra of these cation species of $\mathbf{3}$ and PTDPA were measured (Supporting Information File 1, Figure $\mathrm{S} 15)$. Contrary to the absorption spectra, there is no distinctive ellipticity based on the cationic species of TTF in any cationic species derived from 3 or PTDPA. Only small changes of $\lambda_{\text {first }}$ and $\lambda_{\text {second }}$ peaks, mainly associated with the 1,3-diphenylallene framework, were observed during the oxidation reactions. In the present chiral system, the chiroptical effects between two TTF units are small due to the long-range exciton coupling, and hence the Cotton effect derived from the electronic transition of the TTF moiety was not clearly seen. However, both chiral compounds of $\mathbf{3}$ and PTDPA did not undergo the racemization in daylight. Therefore, the chirality was also preserved in the cationic species.

\section{Conclusion}

In this paper, we have shown the synthesis and chiroptical properties of a novel chiral TTF dimer linked by a 1,3-diphenylallene framework for the purpose of the development of a stable chiral source without racemization under ambient conditions. The title compound was synthesized from 1,3-bis(4iodophenyl)-1,3-diisopropylallene (9) and organozinc species derived from 4,5-bis(methylthio)TTF. Optical resolution of the enantiomer 3 and its precursor 9 was achieved by a recyclable HPLC on a chiral stationary phase. The ECD spectra were measured, and the obtained spectra allowed for the validation of the absolute configurations based on the TD-DFT method.
Although the observed Cotton effect associated with TTF moieties is relatively weak, each chiral allene is stable towards the racemization under ambient light. A chiral copolymer based on TTF and a chiral 1,3-diphenylallene as the main chain scaffold (PTDPA) was also prepared using a direct $\mathrm{C}-\mathrm{H}$ activation of the TTF framework. The resultant chiral polymers exhibited the characteristic Cotton effect associated with the central chiral 1,3-diphenylallene moieties. The polymer also did not undergo racemization under daylight. Moreover, electrochemical properties were also investigated by the $\mathrm{CV}$ method. Cationic species were prepared by the addition of $\mathrm{Fe}\left(\mathrm{ClO}_{4}\right)_{3}$ as the oxidant, and their UV and ECD spectra were also recorded. Other molecular designs, including a copolymer based on the 1,3-diphenylallene units, are currently underway to create valuable chiral molecules.

\section{Experimental}

4,5-Bis(methylthio)TTF was prepared according to literature procedures [19]. Dehydrated THF and $\mathrm{Et}_{2} \mathrm{O}$ were purchased from Wako Pure Chemical Industries, LTd. (Super Dehydrated, Stabilizer Free, $\mathrm{H}_{2} \mathrm{O}<10 \mathrm{ppm}$ ). Anhydrous $\mathrm{ZnCl}_{2}$ (99\%) was purchased from Wako Pure Chemical Industries, and dried in vacuo for $4 \mathrm{~h}$ with heating over $220{ }^{\circ} \mathrm{C}$. Other commercially available materials were used as received. Column chromatography was carried out using Kanto chemical silica gel $60 \mathrm{~N}$, 60-210 $\mu \mathrm{m}$ meshes. ${ }^{1} \mathrm{H}$ and ${ }^{13} \mathrm{C}$ NMR spectra were recorded on Bruker AVANCE-III-400 (400 MHz for ${ }^{1} \mathrm{H}, 100 \mathrm{MHz}$ for ${ }^{13} \mathrm{C}$ ) or on Bruker AVANCE-III-600 (600 MHz for ${ }^{1} \mathrm{H}, 150 \mathrm{MHz}$ for ${ }^{13} \mathrm{C}$ ). Spectra are reported (in $\delta$ ) referenced to internal $\mathrm{Me}_{4} \mathrm{Si}$. Mass spectra were recorded on Thermo Scientific, Exactive Plus Orbitrap Mass Spectrometer with atmospheric pressure chemical ionization (APCI) probe. IR spectra were recorded on JASCO FT/IR-610 spectrometer. Melting points were determined with Yanaco melting point apparatus. Elemental analyses were performed on Perkin Elmer PE 2400-II CHNA/O analyzer. Optical resolution was carried out with recyclable preparative HPLC (JAI Model LC-9204) equipped with Daicel CHIRALPAK-IA3 column $(20 \varnothing \times 250 \mathrm{~mm})$. The optical rotations were measured with JASCO P-1300 spectropolarimeter in $1 \mathrm{dm}$ quartz cell at $24{ }^{\circ} \mathrm{C}$. Electronic circular dichroism (ECD) spectra were recorded on JASCO J-725 spectrodichrometer. The spectra were combined after the baseline correction of each measurement. cyclic voltammetry $(\mathrm{CV})$ measurements were performed on Hokuto Denko HZ-5000 electrochemical analyzer. GPC analysis for the polymer products was carried out at $40{ }^{\circ} \mathrm{C}$ on a Shodex GPC apparatus equipped with two SB-806M HQ GPC columns (Showa Denko K. K.) and a UV detector. DMF was used as the eluent at a flow rate of $0.5 \mathrm{~mL} / \mathrm{min}$. Polystyrene standards with a narrow distribution of molecular weight $\left(M_{\mathrm{w}}: 580-377,400\right)$ were used for molecular weight calibration. 
Synthesis of 8: To a solid mixture of dried CuI (5.7 g, $30 \mathrm{mmol})$ and $\mathrm{LiBr}(2.6 \mathrm{~g}, 30 \mathrm{mmol})$ was added dropwise acetyl ester 7 (6.7 g, $15 \mathrm{mmol})$ in THF $(170 \mathrm{~mL})$ during $15 \mathrm{~min}$ at rt, and the mixture was cooled to $-78{ }^{\circ} \mathrm{C}$. Then, freshly prepared iPrMgCl $(30 \mathrm{mmol})$ in THF $(15 \mathrm{~mL})$ was added dropwise into the mixture at $-78^{\circ} \mathrm{C}$. After stirring for $1 \mathrm{~h}$ at $-78^{\circ} \mathrm{C}$, the mixture was further stirred for $14 \mathrm{~h}$ at $\mathrm{rt}$. The resultant mixture was poured into saturated aqueous $\mathrm{NH}_{4} \mathrm{Cl}$ solution, and the products were extracted by $\mathrm{Et}_{2} \mathrm{O}$. The organic phase was washed with brine and dried over $\mathrm{MgSO}_{4}$. After evaporation, the crude products were purified on silica gel column chromatography with the elution of hexane. Removal of the solvent afforded $\mathbf{8}$ as colourless oil (5.8 g, 90\%): MS (GC) $m / z=432\left(50 \%, \mathrm{M}^{+}\right.$: $\left.\mathrm{C}_{21} \mathrm{H}_{22}{ }^{79} \mathrm{Br}_{2}\right), 434\left(100 \%, \mathrm{M}^{+}: \mathrm{C}_{21} \mathrm{H}_{22}{ }^{79} \mathrm{Br}^{81} \mathrm{Br}\right)$, and 436 $\left(50 \%, \mathrm{M}^{+}: \mathrm{C}_{21} \mathrm{H}_{22}{ }^{81} \mathrm{Br}_{2}\right) ;{ }^{1} \mathrm{H}$ NMR $\left(400 \mathrm{MHz}, \mathrm{CDCl}_{3}\right) \delta 7.42$ (d, $J=8.6 \mathrm{~Hz}, 2 \mathrm{H}), 7.27$ (d, $J=8.6 \mathrm{~Hz}, 2 \mathrm{H}), 2.91$ (septet, $J=6.8 \mathrm{~Hz}), 1.17(\mathrm{~d}, J=6.8 \mathrm{~Hz}, 3 \mathrm{H}), 1.15(\mathrm{~d}, J=6.8 \mathrm{~Hz}, 3 \mathrm{H})$; ${ }^{13} \mathrm{C}$ NMR $\left(100 \mathrm{MHz}, \mathrm{CDCl}_{3}\right) \delta 203.0,135.6,131.7,128.0$, 120.7, 117.1, 28.8, 22.7, 22.4; IR (neat): 2961, 2926, 2870, 1919, 1489, 1464, 1074, 1009, $825 \mathrm{~cm}^{-1}$; HRMS (APCI-orbitrap) calcd for $\mathrm{C}_{21} \mathrm{H}_{22} \mathrm{Br}_{2}\left(\mathrm{M}^{+}\right)$432.0088; found, 432.0089 .

Synthesis of 9: To a solution of 1,3-bis(4-bromophenyl)allene derivative $8(1.0 \mathrm{~g}, 2.3 \mathrm{mmol})$ in $\mathrm{Et}_{2} \mathrm{O}(50 \mathrm{~mL})$ was added dropwise $t-\mathrm{C}_{4} \mathrm{H}_{9} \mathrm{Li}(6.0 \mathrm{~mL}, 9.8 \mathrm{mmol})$ at $-78{ }^{\circ} \mathrm{C}$ under Ar atmosphere. After stirring for $30 \mathrm{~min}$ at the same temperature, $\mathrm{C}_{6} \mathrm{~F}_{13} \mathrm{I}$ $(1.3 \mathrm{~mL}, 5.84 \mathrm{mmol})$ was added dropwise by syringe. The resultant mixture was stirred for $3 \mathrm{~h}$ at $-78{ }^{\circ} \mathrm{C}$, and then saturated aqueous $\mathrm{NH}_{4} \mathrm{Cl}$ solution was poured into the solution at $-78^{\circ} \mathrm{C}$. After allowing to warming up to $\mathrm{rt}$, the mixture was extracted by $\mathrm{Et}_{2} \mathrm{O}$. The organic phase was washed with brine and dried over $\mathrm{Na}_{2} \mathrm{SO}_{4}$. After removal of the solvent, the crude product was purified by column chromatography on silica gel with hexane elution to give colourless oil of 9 (1.0 g, 92\%): MS (APCI) $m / z=528\left(\mathrm{M}^{+}\right) ;{ }^{1} \mathrm{H} \mathrm{NMR}\left(400 \mathrm{MHz}, \mathrm{CDCl}_{3}\right) \delta 7.62(\mathrm{~d}$, $J=8.6 \mathrm{~Hz}, 2 \mathrm{H}), 7.14(\mathrm{~d}, J=8.6 \mathrm{~Hz}, 2 \mathrm{H}), 2.94$ (septet, $J=6.7 \mathrm{~Hz}, 1 \mathrm{H}), 1.17(\mathrm{~d}, J=6.8 \mathrm{~Hz}, 2 \mathrm{H}), 1.15(\mathrm{~d}, J=6.8 \mathrm{~Hz}$, $2 \mathrm{H}) ;{ }^{13} \mathrm{C} \mathrm{NMR}\left(100 \mathrm{MHz}, \mathrm{CDCl}_{3}\right) \delta 202.9,137.6,136.0,128.1$, 117.0, 92.2, 28.6, 22.7, 22.4; IR (neat): 2961, 2926, 2869, 1918, $1483,1463,1383,1216 \mathrm{~cm}^{-1}$; HRMS (APCI-orbitrap) calcd for $\mathrm{C}_{21} \mathrm{H}_{22} \mathrm{I}_{2}\left(\mathrm{M}^{+}\right)$527.98108; found, 527.98108.

Synthesis of 3: To a solution of 4,5-bis(methylthio)TTF (640 mg, $2.2 \mathrm{mmol}$ ) [20] in THF (30 mL) was added dropwise $n \mathrm{C}_{4} \mathrm{H}_{9} \mathrm{Li}(1.3 \mathrm{~mL}, 2.2 \mathrm{mmol})$ at $-78^{\circ} \mathrm{C}$ under $\mathrm{Ar}$ atmosphere. After the mixture was stirred for $90 \mathrm{~min}$, a suspension of $\mathrm{ZnCl}_{2}$ (377 mg, $2.8 \mathrm{mmol})$ in THF $(3 \mathrm{~mL})$ was added at $-65^{\circ} \mathrm{C}$. The solution was further stirred for $30 \mathrm{~min}$, then 1,3-bis(4-iodophenyl)allene derivative 9 (458 $\mathrm{mg}, 0.87 \mathrm{mmol})$ in THF $(2.5 \mathrm{~mL})$ and $\mathrm{Pd}\left(\mathrm{PPh}_{3}\right)_{4}(100 \mathrm{mg}, 0.087 \mathrm{mmol})$ were added into the mixture at $-20{ }^{\circ} \mathrm{C}$. The resultant mixture was stirred for $14 \mathrm{~h}$ at $\mathrm{rt}$, and then poured into saturated aqueous $\mathrm{NH}_{4} \mathrm{Cl}$ solution. The product was extracted by $\mathrm{Et}_{2} \mathrm{O}$, and the organic phase was washed with saturated brine and dried over $\mathrm{MgSO}_{4}$. The crude product was purified by column chromatography on silica gel with $\mathrm{CH}_{2} \mathrm{Cl}_{2} /$ hexane $(\mathrm{v} / \mathrm{v}=1: 4)$. Recrystallization from $\mathrm{CH}_{2} \mathrm{Cl}_{2} / \mathrm{MeOH}(\mathrm{v} / \mathrm{v}=1: 1)$ solution gave $3(664 \mathrm{mg}, 89 \%)$ : orange powder; $\mathrm{mp}: 77.8-79.2{ }^{\circ} \mathrm{C}$; $\mathrm{MS}$ (APCI) $\mathrm{m} / \mathrm{z}=865\left(\mathrm{M}^{+}+\right.$ $\mathrm{H}) ;{ }^{1} \mathrm{H} \mathrm{NMR}\left(400 \mathrm{MHz}, \mathrm{CDCl}_{3}\right) \delta 7.40(\mathrm{~d}, J=8.6 \mathrm{~Hz}, 4 \mathrm{H})$, $7.34(\mathrm{~d}, J=8.6 \mathrm{~Hz}, 4 \mathrm{H}), 6.48(\mathrm{~s}, 2 \mathrm{H}), 2.97$ (sept, $J=6.8 \mathrm{~Hz}$, $2 \mathrm{H}), 2.44(\mathrm{~s}, 6 \mathrm{H}), 2.43(\mathrm{~s}, 6 \mathrm{H}), 1.19(\mathrm{t}, J=6.8 \mathrm{~Hz}, 12 \mathrm{H})$; ${ }^{13} \mathrm{C}$ NMR $\left(100 \mathrm{MHz}, \mathrm{CDCl}_{3}\right) \delta 204.2,136.9,136.0,130.8$, $127.8,127.7,126.7,126.6,117.4,114.8,112.8,107.3,28.7$, 22.8, 22.5, 19.4; IR (KBr): 2958, 2918, 2866, 1914, 1568, 1499, $1418,835,759 \mathrm{~cm}^{-1}$; anal. calcd for $\mathrm{C}_{37} \mathrm{H}_{36} \mathrm{~S}_{12}: \mathrm{C}, 51.35 ; \mathrm{H}$, 4.19; found: C, 51.36; H, 4.25 .

Synthesis of $(\boldsymbol{R}) /(\boldsymbol{S})$-PTDPA: A mixture of $\mathrm{Pd}(\mathrm{OAc})_{2}(8.9 \mathrm{mg}$, $40 \mu \mathrm{mol}), \mathrm{P}(t-\mathrm{Bu})_{3} \cdot \mathrm{HBF}_{4}(35 \mathrm{mg}, 120 \mathrm{mmol}), \mathrm{Cs}_{2} \mathrm{CO}_{3}(290$ $\mathrm{mg}, 2.8 \mathrm{mmol})$ in degassed NMP (1 mL) was stirred for $20 \mathrm{~min}$ at $100{ }^{\circ} \mathrm{C}$ under Ar atmosphere. Then, $(R)-3(80 \mathrm{mg}, 151 \mu \mathrm{mol})$ and 4,5-bis(methylthio)TTF (67 mg, $226 \mu \mathrm{mol}$ ) were added to the solution, and the reaction mixture was stirred for 3 days at $100{ }^{\circ} \mathrm{C}$. After cooling to $\mathrm{rt}$, the solvent was removed under reduced pressure, and then the residue and $N, N$-diethylphenylazothioformamide $(100 \mathrm{mg}, 40 \mu \mathrm{mol})$, as a metal scavenger, were dispersed in THF $(2 \mathrm{~mL})$. The resultant suspension was stirred for $30 \mathrm{~min}$ at $\mathrm{rt}$, then further for $1 \mathrm{~h}$ at $100{ }^{\circ} \mathrm{C}$. After cooling at $\mathrm{rt}$, the solution was poured into $\mathrm{CH}_{3} \mathrm{OH}(150 \mathrm{~mL})$. The resulted precipitates were collected by filtration, washing with $\mathrm{CH}_{3} \mathrm{OH}$. The residue on the filter was collected, and then purified by column chromatography on non-polar polystyrene gel (Bio-beads S-X3 Support) with the elution of toluene. The crude product was further purified reprecipitation with toluenehexane, yielding copolymer of $(R)$-PTDPA as an orange-brown powder (24 mg, 26\%). The number-average molecular weight $\left(M_{\mathrm{n}}\right)$ was estimated to be $5.6 \times 10^{3}$, and its distribution $\left(M_{\mathrm{n}} / M_{\mathrm{w}}\right)$ was estimated to be 1.01: orange-brown powder; ${ }^{1} \mathrm{H}$ NMR (400 MHz, $\left.\mathrm{CDCl}_{3}\right) \delta$ 7.13-7.36, 6.46, 2.89, 2.40, 1.14. In similar manner, $(S)$-PTDPA was obtained from the reaction of $(S)-3$ in $31 \%$ yield. Its $M_{\mathrm{n}}$ value was estimated to be $2.8 \times 10^{3}$ and its distribution was estimated to be 1.54 .

\section{Supporting Information}

\section{Supporting Information File 1}

Experimental procedures, characterization data, copies of

${ }^{1} \mathrm{H}$ and ${ }^{13} \mathrm{C}$ NMR charts, recyclable chiral HPLC chart and DFT calculation summary.

[http://www.beilstein-journals.org/bjoc/content/ supplementary/1860-5397-11-109-S1.pdf] 


\section{Acknowledgements}

The authors gratefully acknowledge partial financial aid from Kitasato University Research Grant for young researchers. We also thank to Prof. Dr. Takahiro Tsuchiya for helpful discussion. The calculations were performed at the Research Centre for Computational Science, Okazaki, Japan.

\section{References}

1. Mammana, A.; Carroll, G. T.; Feringa, B. L. Circular dichroism of dynamic systems: switching molecular chirality and supramolecular chirality. In Comprehensive Chiroptical Spectroscopy; Berova, N.; Polavarapu, P. L.; Nakanishi, K.; Eoody, R. S., Eds.; Wiley: Hoboken, NJ, U.S.A., 2012; Vol. 2, pp 289-316.

2. Feringa, B. L.; van Delden, R. A.; Koumura, N.; Geertsema, E. M. Chem. Rev. 2000, 100, 1789-1816. doi:10.1021/cr9900228

3. Canary, J. W. Chem. Soc. Rev. 2009, 38, 747-756. doi:10.1039/b800412a

4. Nishida, J.-i.; Suzuki, T.; Ohkita, M.; Tsuji, T. Angew. Chem., Int. Ed. 2001, 40, 3251-3254. doi:10.1002/1521-3773(20010903)40:17<3251::AID-ANIE3251>3.0.CO ;2-P

5. Deng, J.; Song, N.; Zhou, Q.; Su, Z. Org. Lett. 2007, 9, 5393-5396. doi:10.1021/ol701822u

6. Pospíšil, L.; Bednárová, L.; Štěpánek, P.; Slavíček, P.; Vávra, J.; Hromadová, M.; Dlouhá, H.; Tarábek, J.; Teplý, F. J. Am. Chem. Soc. 2014, 136, 10826-10829. doi:10.1021/ja500220j

7. Kobayakawa, K.; Hasegawa, M.; Sasaki, H.; Endo, J.; Matsuzawa, H.; Sako, K.; Yoshida, J.; Mazaki, Y. Chem. - Asian J. 2014, 9 , 2751-2754. doi:10.1002/asia.201402667

8. Diederich, F.; Rivera-Fuentes, P. Angew. Chem., Int. Ed. 2012, 51, 2818-2828. doi:10.1002/anie.201108001

9. Krause, N.; Hashimi, A. S. K., Eds. Modern Allene Chemistry; Wiley-VCH: Weinheim, Germany, 2004.

10. Hasegawa, M.; Sone, Y.; Iwata, S.; Matsuzawa, H.; Mazaki, Y. Org. Lett. 2011, 13, 4688-4691. doi:10.1021/ol201857f

11. Roth, W. R.; Ruf, G.; Ford, P. W. Chem. Ber. 1974, 107, 48-52. doi:10.1002/cber.19741070106

12. Alonso-Gómez, J. L.; Rivera-Fuentes, P.; Seiler, P.; Diederich, F. Chem. - Eur. J. 2008, 14, 10564-10568. doi:10.1002/chem.200801456

13. Odermatt, S.; Alonso-Gómez, L.; Seiler, P.; Cid, M. M.; Diederich, F. Angew. Chem., Int. Ed. 2005, 44, 5074-5078. doi:10.1002/anie.200501621

14. Hasegawa, M.; Iwata, S.; Sone, Y.; Endo, J.; Matsuzawa, H.; Mazaki, Y. Molecules 2014, 19, 2829-2841. doi:10.3390/molecules19032829

15. Thorand, S.; Vögtle, F.; Krause, N. Angew. Chem., Int. Ed. 1999, 38, 3721-3723. doi:10.1002/(SICI)1521-3773(19991216)38:24<3721::AID-ANIE3721>3 .0.CO;2-9

16. Clay, M. D.; Fallis, A. G. Angew. Chem., Int. Ed. 2005, 44, 4039-4042. doi:10.1002/anie.200500484

17. Kijima, M.; Hiroki, K.; Shirakawa, H. Macromol. Rapid Commun. 2002, 23, 901-904. doi:10.1002/1521-3927(20021001)23:15<901::AID-MARC901>3.0.CO; 2-3

18. Pu, X.; Qi, X.; Ready, J. M. J. Am. Chem. Soc. 2009, 131, 10364-10365. doi:10.1021/ja9041127
19. Hasegawa, M.; Daigoku, K.; Hashimoto, K.; Nishikawa, H.; lyoda, M. Bull. Chem. Soc. Jpn. 2012, 85, 51-60. doi:10.1246/bcsj.20110224

20. Berova, N.; Nakanishi, K. Exciton Chirality Method: Principles and Applications. In Circular dichroism: Principles and Applications; Nakanishi, K.; Berova, N.; Eoody, R. W., Eds.; Wiley: Hoboken, NJ, U.S.A., 1994; pp 361-398.

21. Gaussian 09, Revision D.01; Gaussian, Inc.: Wallingford, CT, U.S.A., 2010.

22. Mitamura, Y.; Yorimitsu, H.; Oshima, K.; Osuka, A. Chem. Sci. 2011, 2, 2017-2021. doi:10.1039/c1sc00372k

\section{License and Terms}

This is an Open Access article under the terms of the Creative Commons Attribution License

(http://creativecommons.org/licenses/by/2.0), which permits unrestricted use, distribution, and reproduction in any medium, provided the original work is properly cited.

The license is subject to the Beilstein Journal of Organic Chemistry terms and conditions: (http://www.beilstein-journals.org/bjoc)

The definitive version of this article is the electronic one which can be found at: doi:10.3762/bjoc. 11.109 